\title{
Clinical assessment of a rebreathing method for measuring pulmonary gas transfer
}

\author{
NJ RUSSELL, LR BAGG, J DOBRZYNSKI, DTD HUGHES \\ From the Department of Thoracic Medicine, London Hospital, London
}

ABSTRACT A rebreathing method for measuring carbon monoxide transfer factor (TLCO) and transfer coefficient (KCO) is evaluated. The test was performed on 42 subjects. Seventeen of these had normal lung function while the remainder suffered from various conditions, most having fibrosing alveolitis. No patients with severe airways obstruction were included in the group. The results were compared with single-breath measurements and close correlations were found between single-breath $\mathrm{KCO}$ and rebreathing $\mathrm{KCO}(\mathrm{r}=0.78, \mathrm{p}<0.001)$ and between single-breath TLCO and rebreathing TLCO $(r=0.97, \mathrm{p}<0.001)$. The reasons for discrepancies between single-breath and rebreathing values are discussed. It is concluded that measurement of rebreathing gas transfer is a useful supplement to routine tests of lung function, particularly in breathless patients with a small vital capacity.

Determining the pulmonary capacity for carbon monoxide (TLCO) and the transfer coefficient (KCO) is now a standard procedure in most pulmonary function laboratories. The single-breath method of Krogh, ${ }^{1}$ modified by Ogilvie et al ${ }^{2}$ which has found wide acceptance throughout the United Kingdom, is quick, relatively easy to perform, and reproducible. It requires subjects to hold their breath for $10 \mathrm{sec}-$ onds, however, have a vital capcity greater than 1.3 1 , and be sufficiently mobile to attend the lung function laboratory. In our practice we see some patients who do not fulfil these requirements. Clark et $a l^{3}$ introduced a bedside rebreathing technique for measuring pulmonary carbon monoxide uptake, primarily intended for patients with suspected intra-alveolar haemorrhage, who are frequently too ill to undertake the single-breath test. We have applied the same method to a study of normal volunteers and patients with impaired lung function, and compared the results with those obtained by the single-breath procedure.

\section{Methods}

All subjects had measurements of forced expiratory volume in one second $\left(\mathrm{FEV}_{1}\right)$, forced vital capacity (FVC), peak expiratory flow rate (PEFR), rebreathing carbon dioxide tension $\left(\mathrm{PCO}_{2}\right)$, lung volume

Address for reprint requests: Dr DTD Hughes, London Hospital, Whitechapel, London E1 1BB. (by closed-circuit helium dilution), single-breath transfer factor for carbon monoxide (TLCOSB) (with the modifications of Jones and Meade ${ }^{4}$, and transfer coefficient (KCOSB) (by the method of McGrath and Thomson ${ }^{5}$ ). Rebreathing KCO (KCORB) was measured by the method of Clark et al. ${ }^{3}$ A 1-litre syringe is connected via a two-way tap to a 1-litre anaesthetic bag. After the dead space has been flushed the system is filled with the helium and carbon monoxide gas mixture as in the single-breath method (about $10 \% \mathrm{He}$ and $0.3 \% \mathrm{CO}$ ). When the gas has been thoroughly mixed and sampled, the anaesthetic bag is emptied and refilled with $0.75 \mathrm{l}$ of the gas mixture from the syringe. A mouthpiece is fitted in place of the syringe and with the nose clip applied and the two-way tap open to the atmosphere the subject breathes through the system. At the end of a quiet, tidal expiration the two-way tap is turned so that the subject rebreathes from the bag, emptying it with each inhalation, at a rate of one cycle per second. The exact time for 10 cycles is recorded with a stop watch, and the bag is closed at the end of the tenth expiration. The gas inside is analysed for helium and carbon monoxide.

The rate of uptake of carbon monoxide from alveolar gas is calculated from the equation of Krogh $^{1}$ :

$\mathrm{KCO}=\log _{\mathrm{e}} \frac{\mathrm{F}_{\mathrm{I}} \mathrm{CO} \times \mathrm{F}_{\mathrm{E}} \mathrm{He}}{\mathrm{F}_{\mathrm{E}} \mathrm{CO} \times \mathrm{F}_{\mathrm{I}} \mathrm{He}} \times \frac{23 \cdot 3}{t}$,

where $\mathrm{F}_{\mathrm{I}} \mathrm{CO}=$ fractional carbon monoxide concentra- 
tion in the bag at the start of rebreathing; $\mathrm{F}_{\mathrm{E}} \mathrm{CO}=$ fractional carbon monoxide concentration in the bag at the end of the rebreathing period; $\mathrm{F}_{\mathrm{I}} \mathrm{He}=$ fractional helium concentration in the bag at the start of rebreathing; $\mathrm{F}_{\mathrm{E}} \mathrm{He}=$ fractional helium concentration at the end of rebreathing; $t=$ rebreathing time in seconds. The figure 23.3 is a combined correction factor converting from millilitres to millimoles, from seconds to minutes, from fractional concentration to partial pressure of dry gas in kilopascals, and from BTPS to STPD (the latter is required because carbon monoxide uptake is expressed in millilitres or millimoles STPD by convention); it is equal to

$$
\frac{1000 \times 60 \times 0.826}{22.4 \times 95.0} \text {. }
$$

The units for KCO are mmol (STPD) $\min ^{-1} \mathrm{kPa}^{-1}$ l(BTPS $)^{-1}$ and the value is equivalent to TLCO/VA, where VA is the alveolar volume (in l(BTPS)) at which the measurement is made. VA may be calculated from the dilution of helium in the bag after rebreathing:

$\mathrm{V}_{\mathrm{A}_{\mathrm{BTPS}}}=\frac{\mathrm{F}_{\mathrm{I}} \mathrm{He} \times 0.75}{\mathrm{~F}_{\mathrm{E}} \mathrm{He}} \times 1.1$.

It is equal to VBAG + VLUNG. $1 \cdot 1$ is an approximate ATP-to-BTPS conversion factor.

The diffusing capacity (TLCORB) may be calculated from $\mathrm{KCORB} \times \mathrm{VA}$, and its units are mmol(STPD) $\min ^{-1} \mathrm{kPa}^{-1}$.

The technique also allows for a measurement of the subject's functional residual capacity (FRCRB), which is the volume at which the subject starts rebreathing. It is calculated from the dilution of helium:

FRCRB $=\frac{F_{\mathrm{I}} \mathrm{He} \times 0.75}{\mathrm{~F}_{\mathrm{E}} \mathrm{He}}-(\mathrm{VB}+\mathrm{VD}) \times 1 \cdot 1$,

where $V_{B}=$ bag volume $(0.751)$ and $V_{D}=$ dead space volume of lung (anatomical and equipment).

These measurements were made in 17 subjects with normal lung function, two of whom were being investigated for breathlessness, and 25 with abnormal lung function (diagnoses listed in the table).
Patients with severe airways obstruction were excluded from the study because it was thought that they would be unable to rebreathe sufficiently rapidly.

Each subject rehearsed the rebreathing method before doing the test. The mean of two valid measurements of rebreathing $\mathrm{KCO}$ was taken from each patient.

\section{Results}

The mean results of TLCOSB, KCOSB (with their percentage of predicted normal values), TLCORB, and KCORB; FRC measured by closed-circuit helium dilution; and FRCRB for the 42 subjects are shown in the table. Values of TLCOSB ranged from 2.7 to $15.56 \mathrm{mmol} \mathrm{min}-1 \mathrm{kPa}^{-1}$ and those of KCOSB from 0.64 to $2.92 \mathrm{mmol} \mathrm{min}^{-1} \mathrm{kPa}^{-1} \mathrm{l}^{-1}$.

The relationship between FRC measured by closed-circuit helium dilution and FRCRB is shown in figure 1 . There is a significant correlation between the values $(r=0.75 ; p<0.001)$, though the rebreathing value (mean FRCRB $=2.96 \mathrm{l}$ ) is lower than the FRC measured by closed-circuit helium dilution (mean FRC $=3.27 \mathrm{l}$ ), particularly at larger lung volumes. The relationship between the two values is expressed by the equation

$$
\text { FRCRB }=0.092+0.878 \text { FRC. }
$$

The scatter diagram for KCOSB against KCORB (fig 2) shows the correlation between the measurements, which is highly significant $(r=0.78 ; p<$ $0 \cdot 001)$. The means of the two sets of values are similar (mean KCOSB $=1.42$; mean KCORB $=1 \cdot 33$ ). The relationship between the two values is given by the regression equation

$$
\mathrm{KCORB}=1 \cdot 179 \mathrm{KCOSB}-0 \cdot 343 .
$$

The highest coefficient of correlation was that between TLCOSB and TLCORB $(r=0.97$; $p<$ 0.001 -fig 3 ). The rebreathing transfer factor measurements (mean TLCORB $=5 \cdot 29$ ) were lower than the single-breath values (mean TLCOSB $=7 \cdot 41$ ), reflecting the fact that the rebreathing technique measures TLCO at a lower alveolar volume (effec-

Mean gas transfer measurements* in 42 patients $\dagger$ undergoing the rebreathing test

\begin{tabular}{llllll}
\hline Age (y) & $\begin{array}{l}\text { FRC closed-circuit } \\
\text { helium dilution }\end{array}$ & FRC rebreathing & $\begin{array}{l}\text { KCOSB } \\
\text { (\% predicted } \\
\text { normal in parentheses) }\end{array}$ & KCORB & $\begin{array}{l}\text { TLCOSB } \\
\text { (\% predicted } \\
\text { normal in parentheses) }\end{array}$ \\
\hline 43.9 & 3.27 & 2.96 & $1.42(82.3)$ & 1.33 & $7.41(75)$ \\
\hline
\end{tabular}

*Functional residual capacity (FRC) in lBTPS, transfer coefficient (KCO) in mmol min-1 $\mathrm{kPa}^{-1} \mathrm{l}^{-1}$, pulmonary diffusing capacity for carbon monoxide (TLCO) in mmol min $^{-1} \mathrm{kPa}^{-1}$. SB indicates the single-breath method and $\mathrm{RB}$ the rebreathing method.

$\dagger$ Twenty-six men and 16 women, suffering from asbestosis (4), asthma (1), bronchiectasis (1), bronchial carcinoma (1), bird fancier's lung (1), chronic bronchitis (1), intra-alveolar haemorrhage (2), fibrosing alveolitis (3), eosinophilic granuloma (1), mixed connective tissue disease (1), mitral valve disease (1), polyarteritis nodosa (1), scleroderma (1), sarcoidosis (4), pulmonary embolism (2) (fuller details obtainable from the authors). 


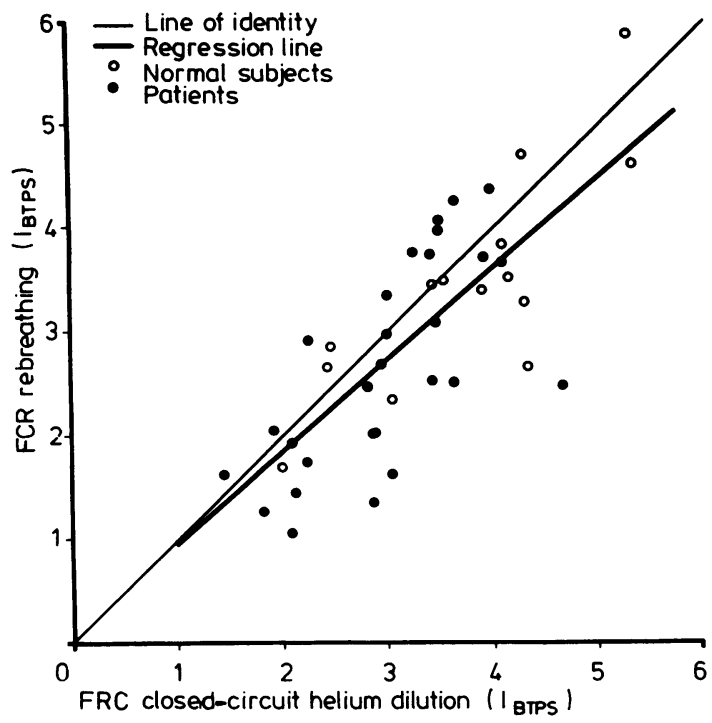

Fig 1 Relationship between functional residual capacity (FRC) measured by closed-circuit helium dilution and by the rebreathing method.

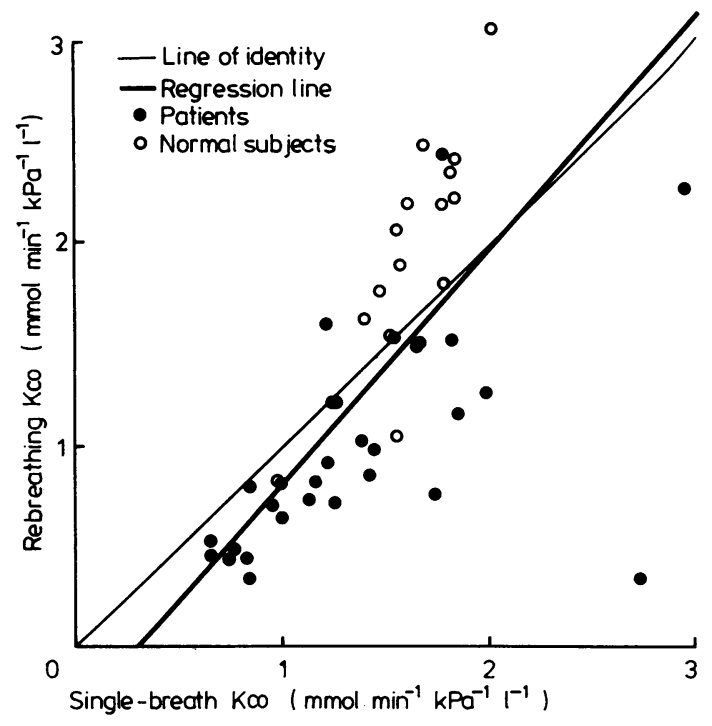

Fig 2 Relationship between the values for the transfer coefficient (KCO) obtained by the single-breath and rebreathing methods.

tively FRC + VB/2) than the single-breath method (about total lung capacity). The relationship between TLCOSB and TLCORB is given by

$$
\text { TLCORB }=1.065 \text { TLCOSB }-2 \cdot 6 \text {. }
$$

The coefficients of variation for 15 duplicate

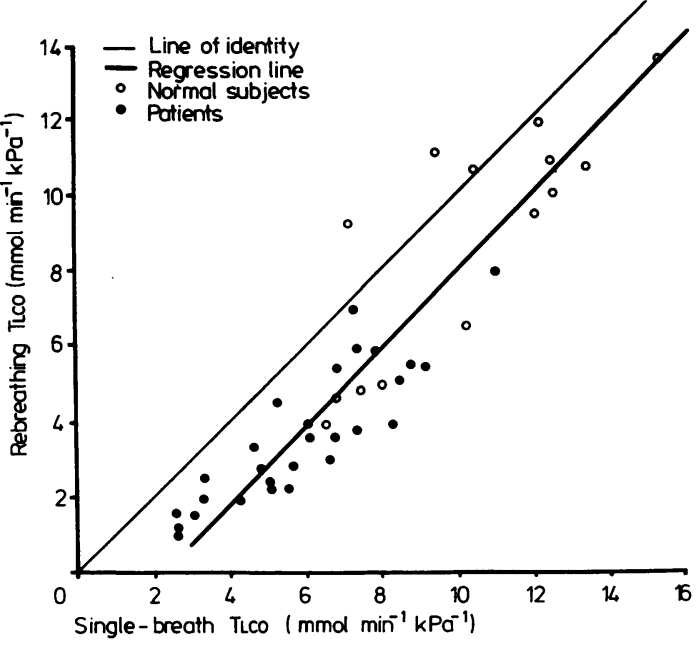

Fig 3 Relationship between the values for the pulmonary diffusing capacity for carbon monoxide (TLCO) obtained by the single-breath and rebreathing methods.

measurements in normal subjects were $8.7 \%$ for KCO, $\mathbf{9 . 1 \%}$ for FRCRB, and $\mathbf{6 . 3 \%}$ for TLCORB.

Most patients, when asked, said that they found the rebreathing method easier to perform than the single-breath method.

\section{Discussion}

The application of a rebreathing method to the measurement of pulmonary carbon monoxide uptake is not a recent innovation..$^{6-8}$ Previous tech-음 niques, however, have suffered from drawbacks that render them impractical in the testing of breathlesso patients or at the bedside. The methods of Kruhof $-\frac{3}{3}$. fer $^{6}$ and Lewis et $a l^{7}$ require elaborate equipmento which is not available in most lung function 3 laboratories, while the method of Marshall ${ }^{8}$ requires윽 a rebreathing volume of 21 and a rebreathing time of 30 seconds-requirements that would preclude을. its use in severely incapacitated patients.

Several assumptions are made when Krogh's equation is applied to a rebreathing system. ${ }^{7}$ The first is ${ }_{0}$ that the mixing of carbon monoxide and helium gas mixture is instantaneous and uniform. This iso assumed also in the single-breath calculation. Gas mixing would be expected to be more complete during rebreathing than in a single inhalation to totalo lung capacity, so this assumption is probably more 0 valid for the rebreathing than for the single-breatho technique. The fact that FRCRB underestimates FRC measured by closed-circuit helium dilution $\mathbb{D}$ indicates that 10 seconds is too short a time for the 
gas to mix throughout the available lung volume when the patient is rebreathing a volume of 0.751 . Secondly, the dead space of subject and equipment is assumed to be negligibly small. Thirdly, the time spent at end-expiration is assumed to be insignificant in relation to the time spent at full inspiration-in other words, the bag is considered an extension of the lung, and the alveolar volume for the calculation of TLCO is taken as VLUNG + VBAG. These second and third assumptions are undoubtedly false; some of the gas mixture spends some of the time exposed to surfaces which are not participating in gas exchange, so the true $\mathrm{KCO}$ will be underestimated. Finally, the rate of uptake of carbon monoxide is assumed to proceed exponentially from the moment rebreathing commences; this is really an extension of the first assumption. Lewis $e t$ $a l^{7}$ showed that in most subjects exponential decline of alveolar carbon monoxide concentration occurs only after about five seconds of rebreathing and may take longer in those with appreciable inequality of ventilation (for example, emphysema). Applying Krogh's equation to a rebreathing system therefore leads to several errors in the estimation of Kco.

There are some important differences between the rebreathing and the single-breath method. McGrath and Thompson ${ }^{5}$ showed that Kco varies inversely with lung volume, so that KCO at rebreathing lung volume (FRC $+\mathrm{VB} / 2)$ should be greater than the single-breath measurement (obtained at about total lung capacity). Furthermore, increased cardiac output during rebreathing and more negative intrathoracic pressure, caused by limitation of inspiration when the bag is empty, might lead to expansion of the pulmonary capillary blood volume and higher values of KCO. Interestingly, measurements of rebreathing $\mathrm{KCO}$ values in our young, healthy volunteers (recruited mostly from medical students) were generally higher than the corresponding single-breath measurements (fig 2). Possibly these normal subjects generate more effort during rebreathing than do patients with impaired lung function; this is due partly to their fitness, which facilitates rapid rebreathing, but also to their desire to impress us with their respiratory prowess. The extra effort leads to an expanded pulmonary blood volume and may account for the higher values of rebreathing Kco seen in this group.

Given all these theoretical limitations, it is suprising that KCOSB agrees so closely with KCORB. KCORB cannot be taken as a measurement equival- ent to KCOSB-the two values indicate the rate of uptake of pulmonary carbon monoxide at different lung volumes and under different physiological conditions. Nevertheless, the highly significant correlation between the two sets of results indicates that factors influencing the single-breath value cause a corresponding change in the rebreathing measurement. We assume that the errors in the rebreathing technique and the calculation outlined above remain fixed for all our subjects, so there is a good linear correlation between the rebreathing and the singlebreath values.

We conclude that measurement of KCO and TLCO by the rebreathing method of Clark $e t a^{3}$ is a useful supplement to routine lung function tests, giving values that correlate closely with single-breath measurements. It has the advantage of simplicity (all the materials should be readily available in most lung function laboratories) and mobility (the measurement can be made at the bedside). It can be used in breathless patients with a small vital capacity and may be particularly useful for serial measurements of gas transfer in patients who become too ill to perform the single-breath test.

\section{References}

${ }^{1}$ Krogh M. The diffusion of gases through the lungs of man. J Physiol 1914/15;49:271-300.

${ }^{2}$ Ogilvie CM, Forster RE, Blakemore WS, Morton JW. A standardised breath-holding technique for the clinical measurement of the diffusing capacity of the lung for carbon monoxide. J Clin Invest 1957;36:1-17.

${ }^{3}$ Clark EH, Jones HA, Hughes JMB. Bedside rebreathing technique for measuring carbon monoxide uptake by the lung. Lancet 1978;i:791-3.

4 Jones RS, Meade F. A theoretical and experimental analysis of abnormalities in estimations of pulmonary diffusing capacity by the single breath method. $Q J$ Exp Physiol 1961;46:131-43.

${ }^{5}$ McGrath MW, Thomson ML. The effect of age, body size and lung volume change on alveolar-capillary permeability and diffusing capacity in man. $J$ Physiol 1959;146:572-82.

- Kruhoffer P. Studies on the lung diffusion coefficient for carbon monoxide in normal human subjects by means of $\mathrm{C}^{14} \mathrm{O}$. Acta Physiol Scand 1954;32:106-23.

${ }^{7}$ Lewis BM, Tai-Hon Lin, Noe FE, Hayford-Welsing EJ. The measurement of pulmonary diffusing capacity for carbon monoxide by a rebreathing method. J Clin Invest 1959;38:2073-86.

${ }^{8}$ Marshall RM. A rebreathing method for measuring carbon monoxide diffusing capacity. Am Rev Respir Dis 1977;115:537-9. 